\title{
PREVALENCE OF OVERWEIGHT AND OBESITY AMONG NURSES IN SCOTLAND: A CROSS-SECTIONAL STUDY USING THE SCOTTISH HEALTH SURVEY
}

\section{ABSTRACT}

Background: Increasing prevalence of overweight and obesity represents a global pandemic. As the largest occupational group in international healthcare systems nurses are at the forefront of health promotion to address this pandemic. However, nurses own health behaviours are known to influence the extent to which they engage in health promotion and the public's confidence in advice offered. Estimating the prevalence of overweight and obesity among nurses is therefore important. However, to date, prevalence estimates have been based on non-representative samples and internationally no studies have compared prevalence of overweight and obesity among nurses to other healthcare professionals using representative data.

Objectives: To estimate overweight and obesity prevalence among nurses in Scotland, and compare to other healthcare professionals and those working in non-heath related occupations.

Design: Cross-sectional study using a nationally representative sample of five aggregated annual rounds (2008-2012) of the Scottish Health Survey.

Setting: Scotland.

Participants: 13,483 adults aged 17 to 65 indicating they had worked in the past 4 weeks, classified in four occupational groups: nurses $(n=411)$, other healthcare professionals $(n=320)$, unqualified care staff $(n=685)$, and individuals employed in non-health related occupations $(n=12,067)$. 
Main outcome measures: Prevalence of overweight and obesity defined as Body Mass Index $\geq 25.0$

Methods: Estimates of overweight and obesity prevalence in each occupational group were calculated with $95 \%$ confidence intervals $(\mathrm{Cl})$. A logistic regression model was then built to compare the odds of being overweight or obese with not being overweight or obese for nurses in comparison to the other occupational categories. Data were analysed using SAS

\subsection{3.}

Results: $69.1 \%(95 \% \mathrm{Cl} 64.6,73.6)$ of Scottish nurses were overweight or obese. Prevalence of overweight and obesity was higher in nurses than other healthcare professionals $(51.3 \%$, $\mathrm{Cl} 45.8,56.7)$, unqualified care staff $(68.5 \%, \mathrm{Cl} 65.0,72.0)$ and those in non-health related occupations (68.9\%, $\mathrm{Cl} 68.1,69.7)$. A logistic regression model adjusted for sociodemographic composition indicated that, compared to nurses, the odds of being overweight or obese was statistically significantly lower for other healthcare professionals (Odds Ratio [OR] 0.45, $\mathrm{Cl} 0.33,0.61$ ) and those in non-health related occupations (OR 0.78, $\mathrm{Cl} 0.62,0.97$ ). Conclusions: Prevalence of overweight and obesity among Scottish nurses is worryingly high, and significantly higher than those in other healthcare professionals and non-health related occupations. High prevalence of overweight and obesity potentially harms nurses' own health and hampers the effectiveness of nurses' health promotion role. Interventions are therefore urgently required to address overweight and obesity among the Scottish nursing workforce.

Key words: Health Promotion; Nurses; Obesity; Scotland; Health Surveys; Workforce Abstract word count: 400 / Manuscript word count: 2,994 


\section{INTRODUCTION}

Increasing prevalence of people who are overweight or obese represents a global pandemic [1]. Between 1980 and 2013 the proportion of overweight and obese adults, defined as those with a Body Mass Index $(\mathrm{BMI}) \geq 25.0$, increased worldwide by $27.5 \%$ [2]. In the United Kingdom (UK), two thirds of the male population (66.6\%) and over a half of females (57.2\%) are overweight or obese [2], and in Scotland $68.2 \%$ of males and $60.4 \%$ of females are overweight or obese [3]. Increasing prevalence is concerning due to the links between being overweight or obese and morbidity and its impacts on health care budgets. Obesity has been associated with increased risk of heart disease [4,5], diabetes mellitus [6], cancer $[7,8]$, lower back injury [9], and reduced health-related quality of life [10]. The estimated cost of overweight and obesity to the UK National Health Service (NHS) is currently $f 6$ billion, and will likely increase to between $f 10$ billion and $£ 12$ billion by 2030 [11]. In Scotland, in $2007 / 08$ the costs of overweight and obesity to the NHS were estimated at $f 312$ million and obesity alone cost NHS Scotland $f 175$ million, equivalent to $2 \%$ of the total budget allocated to NHS Boards [12]. Given these health and financial impacts UK Governments have committed to addressing overweight and obesity as a public health priority [12]. This raises an important question for health care professionals around what their contribution to these public health goals may be.

Nurses have an established and expanding public health role $[13,14]$ and a regulatory requirement to engage in health promotion with their patients [15]. Seizing 'teachable moments' during routine patient interactions to provide health education is understood to be a key element in promoting positive behaviour change [16]. As the largest occupational group in the NHS $[17,18]$ nurses therefore play a pivotal role in addressing the pandemic 
through provision of advice and education around protective behaviours, including the importance of maintaining a healthy diet and frequent participation in physical activity. However, it is known that nurses' own levels of physical activity are associated with the frequency of provision of exercise advice [19]. Evidence also suggests that nurses have a role modelling effect insofar as the public are less confident in overweight nurses' ability to provide advice about diet and exercise [20]. Despite this, in comparison to 'normal' weight nurses, overweight nurses perceive themselves to be equally competent to provide advice and counselling [21] and to hold more positive attitudes towards obese patients [22]. Hence, personal experience might enhance the care provided during interactions between overweight nurses and patients [23]. However, given the potential impact on both their own health and the potentially adverse impact on engagement in health education, estimating the prevalence of overweight or obese among nurses is important.

Reported prevalence of overweight and obesity among nurses internationally ranges between $54.5 \%$ and $79.1 \%[21,24-26]$. Prevalence has been observed to be lowest in the United States of America (USA) (54.5\% [21]; 57\% [24]), followed by the UK (59.1\%), Australia (61.3\%) and New Zealand (61.8\%) [25], and highest in South Africa (79.1\%) [26]. Prevalence of overweight and obesity among nurses in Scotland is not known. International studies comparing obesity prevalence among nurses with the general population have been equivocal, reporting higher prevalence in the UK, Australia and New Zealand [25], comparable prevalence in South Africa [26] and lower prevalence in the USA [21,24]. Prevalence estimates have, however, been based on non-representative samples and to our knowledge no studies have compared prevalence of overweight and obesity among nurses to other healthcare professionals. The aim of this study is to estimate the prevalence of 
overweight and obesity among nurses in Scotland using representative administrative data, and compare prevalence to other healthcare professionals and the general working population. The study represents a step towards assessing the extent to which health care professionals, and especially nurses, are able to effectively contribute to the delivery of health education to address the obesity pandemic.

\section{METHODS}

\section{Study design and participants}

Analysis was conducted using the Scottish Health Survey, a cross-sectional survey of the Scottish population designed by the Scottish Government to yield a nationally representative sample. The Scottish Health Survey is used to estimate prevalence of health conditions, disease risk factors, track health trends over time and measure government performance against targets. Sampling, recruitment and data collection processes used in the Scottish Health Survey are described in detail elsewhere [27]. Briefly, the Scottish Health Survey samples households from the Postcode Address File which contains addresses of most residential dwellings within Scotland. All adults (aged 16 years old or over) in selected households were eligible for interview. Computer-Assisted Personal Interviewing was used for face-to-face data collection in respondent's homes, with questions of a sensitive nature asked via a self-completion booklet.

Five annual rounds of the Scottish Health Survey (2008 to 2012) were aggregated to ensure sufficient numbers for analysis. Only participants aged 17 to 65 years who had worked in the past 4 weeks were included in order that comparisons were of the working population only. 


\section{Measures}

Overweight and obesity

Interviewers measured participants' height and weight from which BMI was derived [28].

Following the World Health Organisation (WHO) classification, BMI was categorised as 'underweight' (BMI<18.5), 'normal' (BMI=18.5-24.9), 'overweight' (BMI=25.0-29.9) and 'obese' (BMI $\geq 30)$. Due to small numbers 'underweight' and 'normal' were aggregated into a single category for analysis.

Occupation

Participants were asked their occupation, which was then classified using the standard occupational classification SOC2000 (for survey years 2008-2011) and SOC2010 (2012). This typology classifies people into specific groups indicating their main work, for example registered nurses [29]. For the purposes of this study, Scottish Health Survey analysts created a variable indicating whether participants were members of four groups: nurses; other healthcare professionals; care workers; and, non-health related occupations. SOC2000 and SOC2010 codes used to create each occupational group are shown in Table 1.

\section{[Insert Table 1 here]}

Socio-demographic characteristics

To take into account compositional differences between these four groups likely to influence weight, data on gender, age, and parental socio-economic status were used for analysis. The National Statistics Socio-Economic Classification provides indication of socioeconomic status [30]. However, as this is an occupation-based classification system all 
nurses are classified in Group 2 of the 5-fold National Statistics Socio-Economic

Classification. This does not, however, reflect the heterogeneity within the nursing workforce. Socio-economic circumstances during childhood have been found to increase risk of obesity in adulthood, especially among women from manual social classes [31]. Hence, inclusion of an individual (rather than area-based) proxy for socio-economic status was deemed preferable to omission of such a measure. Respondents in the Scottish Health Survey were asked to report parental occupation at the age of 14 years old, from which a measure of parental social class was derived. This indicator was used in analysis to take into account differences between groups with regards to socio-economic status.

\section{Statistical methods}

Descriptive statistics for socio-demographic variables were calculated for each of the groups, specifically gender, age, parental social class, as well as for Scottish Health Survey round. Estimates of overweight and obese prevalence in each group were then calculated, with 95\% confidence intervals $(\mathrm{Cl})$. A logistic regression model was then developed to compare the odds of being overweight or obesity with not being overweight or obese for nurses in comparison to the other occupational categories. Survey round and sociodemographic variables were simultaneously entered into the final model to assess the extent to which they explained differences identified in unadjusted models. No evidence of collinearity between variables entered into models was found. Data were analysed using SAS 9.1.3 (SAS Institute, Cary, NC, USA).

Sensitivity analysis 
To account for: (1) sampling and non-response biases in the Scottish Health Survey; (2) the gender imbalance in the nursing workforce, sensitivity analyses were conducted as follows. First, using a weighting variable developed by Scottish Government analysts, models were built using both unweighted and weighted data. Second, models were built using both weighted and unweighted data including men and women, and for women only. Results were similar for unweighted and weighted analyses, and for a model with women only. To ensure reporting reflects the entire nursing workforce (i.e., men are not excluded) results are presented for models including both men and women. Both unweighted and weighted estimates have been tabulated in the interests of transparent reporting.

\section{RESULTS}

\section{Sample}

The initial dataset included 43,524 people after aggregating. Including only those who were aged 17-65 years and who had worked in the previous four weeks reduced this number to 17,294 individuals. Initial analysis found a number of individuals for whom data was missing. Excluding these people from the analysis left a total of 13,483 people in the final dataset for analysis.

The sample included 411 (3.0\%) nurses, 320 (2.2\%) other healthcare professionals, 685 (5.1\%) care workers, and 12,067 (89.5\%) in non-health related occupations (Table 2). For nurses, the majority were female $(92.5 \%, n=380)$, with a mean age of 45.95 years $(95 \% \mathrm{Cl}$ 44.02-45.89).

[Insert Table 2 here] 


\section{Overweight and obesity prevalence}

Over two-thirds of nurses $(69.1 \%, 95 \% \mathrm{Cl} 64.6,73.6)$ were overweight or obese (Table 3). Prevalence of overweight and obesity was higher in nurses than other healthcare professionals $(51.3 \%, 95 \% \mathrm{Cl} 45.8,56.7)$, although over half of that comparison group nonetheless had a BMI indicating them to be above a healthy weight. Unqualified care staff $(68.5 \%, 95 \% \mathrm{Cl} 65.0,72.0)$ and those in non-health related occupations $(68.9 \%, 95 \% \mathrm{Cl} 68.1$, 69.7) had a similar prevalence to that of nurses.

[Insert Table 3 here]

A logistic regression model adjusted for socio-demographic composition indicated that, compared to nurses, the odds of being overweight or obese were statistically significantly lower for other healthcare professionals (Odds Ratio [OR] 0.45, $\mathrm{Cl} 0.33,0.61$ ) and those in non-health related occupations (OR 0.78, $\mathrm{Cl} 0.62,0.97$ ) (Table 4).

[Insert Table 4 here]

\section{DISCUSSION}

Our study found a high prevalence of nurses in the Scottish workforce to be overweight or obese: 7 in 10 (69.1\%) nurses in Scotland were overweight or obese; 4 in 10 were overweight (39.7\%) and 3 in 10 obese (29.4\%). Prevalence of overweight and obesity is therefore higher among nurses in Scotland than those in the UK [25], Australia [25], New 
Zealand [25], and the USA $[21,24]$. Moreover, our study found that other healthcare professionals and those working in non-health related occupations had statistically significantly lower odds of being overweight or obese than nurses. This confirms previous international research that found higher prevalence of overweight and obesity among nurses than the general population in the UK, Australia and New Zealand [25].

Reasons for increased prevalence of overweight and obesity among Scottish nurses are unknown and warrant further investigation, but likely result from a combination of individuals' health-related behaviours and occupational factors. Poor diet and low levels of physical activity are known risk factors for overweight and obesity [32]. Research has found that qualified nurses in the UK have poor health-related behaviours. For example, a study of 551 registered nurses in England found that just under half (45.4\%) did not meet government physical activity guidelines, over half (58.0\%) did not consume the recommended five portions of fruit or vegetables each day, and over a third (36.3\%) ate foods high in fat and sugar content on a daily basis [33]. Hence, individuals' healthbehaviours may be driving the pattern of overweight and obesity observed.

However, occupational factors, specifically nurses' working patterns and access to healthy food in the workplace, may also influence overweight and obesity prevalence. Shift work disrupts regular sleep, eating and exercise habits, potentially making in more difficult to maintain a healthy weight [34]. A systematic review found that shift work is associated with poorer nutritional intake and increased BMI [35]. In the longer-term shift work has been found to increase the risk of chronic diseases, including breast cancer, cardiovascular disease, and diabetes [10], as well as gastrointestinal disturbances [36] and depression [37]. 
Moreover, access to healthy food has been acknowledged as a barrier to nurses and other healthcare professionals serving as healthy role models for patients, and development of health-promoting workplaces is a central component of current NHS strategy [38].

However, shift work may not explain the disparity between Scotland and other countries where prevalence of overweight and obesity is lower. Further research is therefore required that compares prevalence of overweight and obesity among nurses with other occupational groups who work shifts. Most immediately, cross-national research is needed to compare findings from Scotland to other countries - especially the USA - where, despite similar shift-based working patterns, prevalence of overweight and obesity is lower among nurses than the general working population $[21,24]$. Moreover, access to healthy foods in the workplace may not explain differences observed between healthcare professionals potentially working in the same location. Hence, research is needed to understand dietary behaviours of different health professional groups and potential differences across different workplaces to determine the influence of local food landscapes and cultures on patterns of prevalence of overweight and obesity among nurses and other healthcare professionals.

\section{Implications for policy and practice}

Our findings have important implications for health promotion policy, nurse education, and the development of supportive workplace interventions for nurses. First, set in the context of evidence that identifies individuals are less likely to be confident in overweight nurses' ability to provide advice about diet and exercise [20], the high levels of overweight and obesity observed in our study raises some concerns about the effectiveness of health promotion that is reliant on seizing 'teachable moments' during routine patient interactions 
[16]. This is of particular note due to Scotland's poor health record, and the need for health professionals to be fully engaged in public health roles. It has been suggested, however, that previous personal experience of being overweight can enhance supportive patientprofessional relationships [23]. Hence, supporting nurses with their own weight loss has potential to enhance the authenticity of future interactions with patients that draws on such experience which may result in more effective health promotion interventions. In addition, harnessing shared experience may open opportunities for mutual support between patients and professionals, thereby taking seriously the two-way nature of patient-professional interactions and maximising the influence of relational health promotion approaches for both parties.

Second, our findings suggest that nurse education may afford an opportunity to seize the 'teachable moment' nursing curricula provide to promote healthy behaviours and establish healthy habits for the future. Although little is known about the health of student nurses on entry to nursing programmes in Scotland, a cross-sectional study of 325 student nurses in England found that over a quarter (27.1\%) were overweight or obese [39] and a survey of 215 student nurses in Wales found $40 \%$ were overweight to morbidly obese [40]. It is known that the health-related behaviours of student nurses are poor on entry to undergraduate nursing programmes in the UK [39], and generally worse than those of qualified nurses [33]. Less than a quarter (23.8\%) of student nurses in Hawker's (2012) study [40] and under half of student nurses (46.0\%) in Blake et al's study did not meet current physical government guidelines for physical activity, and over three-quarters (76.8\%) did not consume five servings of fruit and vegetables a day [39]. Hence, our findings suggest that commissioners and providers of nurse education - especially in Scotland - 
should consider ways through which undergraduate programmes can be designed to promote healthy behaviours and attitudes among the future nursing workforce in order to reverse high overweight and obesity prevalence. For example, curricula might incorporate more teaching about nurses own health behaviours as well as opportunities to establish healthy habits through timetabled or extra-curricular exercise classes, campuses might incentivise and normalise healthy food choices, and educators might consider how their own role modelling influences students' health-related behaviours.

Third, given links between being overweight or obese and morbidity, the findings are also concerning with regards to the welfare of nurses. Our findings raise important questions around the importance of health literacy as a trigger to individual action. Given their health promotion role, nurses are likely highly health literate and aware of the behavioural steps required to maintain a healthy weight. That such high prevalence of overweight and obesity is evident among a health literature group, suggests that either cognitive dissonance or structural factors may be more influential than health knowledge. There is therefore an urgent need to better understand the reasons for increased prevalence of overweight and obesity among both nursing staff and nursing students through future research in order to better support the Scottish nursing workforce. Research is important in order to ensure that the underlying reasons for nurses' health-related behaviour and the perceived barriers to health promotion among the nursing workforce can inform the development of supportive workplace interventions to address high levels of overweight and obesity observed among the existing workforce. Maintaining and improving the health of the nursing workforce in Scotland is vital due to the workforce and public health implications of our findings. High prevalence of overweight and obesity and associated health problems 
may lead to increased sick leave or premature workforce exit, and hamper nurses' public health role [14] through the implicit messages nurses convey to patients as a 'point of reference' [39] for health-related behaviours.

\section{Strengths and weaknesses}

This is the first study internationally to use nationally representative routinely collected data to estimate the prevalence of overweight and obesity among nurses, and to compare prevalence between health professionals and the general working population. A key strength is that comparisons between occupational groups are made using data drawn from the same survey rather than through reference to population level data derived from different datasets as previous conducted [25]. Moreover, BMI was calculated from height and weight measurements taken by survey interviewers rather than participant self-report increasing their accuracy. However, our study has a number of limitations. First, analyses used cross-sectional data preventing assessment of change in individuals BMI over time or determination of causal factors resulting in overweight and obesity. Comparison of our findings among qualified nurses with recent data for student nurses [39] suggests that it could be that higher prevalence of overweight and obesity among qualified nurses than other healthcare professionals and those in non-health related occupations could be a result of high levels of overweight and obesity on entry to nurse education. However, further longitudinal research using representative samples of student and qualified nurses is required to assess change in overweight and obesity prevalence over time and underlying causal factors. Second, survey data were aggregated for a five-year period (i.e., 2008-2012) and may not account for changes in overweight and obesity prevalence over time. Survey year was included in logistic regression models to control for this and no significant effect 
was observed. Currently, there is no nationally representative dataset in the UK that includes a sufficiently large cohort of nurses to estimate prevalence or overweight and obesity at a single time point. Third, data were missing for some participants for BMI (13.0\%), occupation (0.4\%), and parental social class (10.2\%). It is possible that bias will have influenced results. For example, there may be differences between occupational categories in respect to whether or not individuals declined to provide height and weight data from which BMI was derived. This likely means that BMI data was not missing at random and that estimates are conservative (i.e. differences may be greater than reported).

\section{Conclusions}

Over two-thirds of Scottish nurses were found to be overweight or obese. Prevalence of overweight and obesity among the Scottish nursing workforce was found to be statistically significantly higher than other healthcare professionals and those in non-health related occupations. Observed prevalence was higher than previous studies in the UK, Australia and New Zealand. High prevalence of overweight and obesity potentially harms nurses' own health and hampers the effectiveness of health promotion reliant on relational approaches. Hence, interventions at an individual and structural level are urgently required to address prevalence of overweight and obesity among the nursing workforce in order to better support the nursing workforce and realise the potential public health benefits nurses can have at a population-level through their established health promotion role.

\section{Competing interests}

All authors declare that they have no competing interests. 


\section{Ethical approval}

The study was approved by a University Research Ethics Committee [blinded for peer review].

\section{Data sharing statement}

Data were provided and downloaded from the UK Data Archive.

\section{Funding statement}

This study was not externally funded.

\section{REFERENCES}

1. Swinburn, B. A., Sacks, G., Hall, K. D., McPherson, K., Finegood, D. T., Moodie, M. L., \& Gortmaker, S. L. (2011). The global obesity pandemic: shaped by global drivers and local environments. The Lancet, 378(9793), 804-814.

2. Ng, M., Fleming, T., Robinson, M., Thomson, B., Graetz, N., Margono, C., ... \& Gupta, R. (2014). Global, regional, and national prevalence of overweight and obesity in children and adults during 1980-2013: a systematic analysis for the Global Burden of Disease Study 2013. The Lancet, 384(9945), 766-781.

3. Scottish Government (2012) The Scottish Health Survey 2012: Volume 1, Edinburgh, National Statistics for Scotland, http://www.gov.scot/resource/0043/00434590.pdf (last accessed 2nd March, 2015).

4. Must, A., Spadano, J., Coakley, E. H., Field, A. E., Colditz, G., \& Dietz, W. H. (1999). The disease burden associated with overweight and obesity. JAMA,282(16), 1523-1529. 
5. Global Burden of Metabolic Risk Factors for Chronic Diseases Collaboration (BMI Mediated Effects), Lu, Y., Hajifathalian, K., Ezzati, M., Woodward, M., Rimm, E.B. and Danaei, G. (2014). Metabolic mediators of the effects of body-mass index, overweight, and obesity on coronary heart disease and stroke: a pooled analysis of 97 prospective cohorts with 1.8 million participants. The Lancet, 383(9921), 970-983.

6. Mokdad, A. H., Ford, E. S., Bowman, B. A., Dietz, W. H., Vinicor, F., Bales, V. S., \& Marks, J. S. (2003). Prevalence of obesity, diabetes, and obesity-related health risk factors, 2001. JAMA, 289(1), 76-79.

7. Pan, S. Y., Johnson, K. C., Ugnat, A. M., Wen, S. W., \& Mao, Y. (2004). Association of obesity and cancer risk in Canada. American Journal of Epidemiology, 159(3), 259-268.

8. Renehan, A. G., Tyson, M., Egger, M., Heller, R. F., \& Zwahlen, M. (2008). Body-mass index and incidence of cancer: a systematic review and meta-analysis of prospective observational studies. The Lancet, 371(9612), 569-578.

9. Shiri, R., Karppinen, J., Leino-Arjas, P., Solovieva, S., \& Viikari-Juntura, E. (2010). The association between obesity and low back pain: a meta-analysis.American Journal of Epidemiology, 171(2), 135-154.

10. Wang, X. S., Armstrong, M. E. G., Cairns, B. J., Key, T. J., \& Travis, R. C. (2011). Shift work and chronic disease: the epidemiological evidence. Occupational Medicine, 61(2), 78-89.

11. Dobbs, R., Sawers, C., Thompson, F., Manyika, J., Child, P., McKenna, S., Spatharou, A. (2014). Overcoming obesity: an initial economic analysis. London: McKinsey Global Institute.

12. Scottish Government. (2010). Obesity in Scotland: a route map towards healthy weight. Scottish Government: Edinburgh. 
13. Whitehead, D. (2005). Health promoting hospitals: the role and function of nursing. Journal of Clinical Nursing, 14(1), 20-27.

14. Bücher A, Siversten B, White J (2009) Nurses and midwives: a force for health. Geneva: World Health Organisation.

15. Nursing and Midwifery Council (NMC). (2008). The Code: Standards of conduct, performance and ethics for nurses and midwives. NMC; London.

16. Lawson, P. J., \& Flocke, S. A. (2009). Teachable moments for health behavior change: a concept analysis. Patient Education and Counselling, 76(1), 25-30.

17. Health and Social Care Information Centre (HSCIC). (2014). NHS workforce: summary of staff in the NHS: results from September 2013 census. Leeds: HSCIC.

18. Information Services Division. (2014). NHS Scotland workforce statistics. Online at: https://isdscotland.scot.nhs.uk/Workforce/Publications/2014-0225/Nursing_and_Midwifery_sip_d2013.xls (Last accessed: 21 March 2014).

19. Lobelo, F., \& de Quevedo, I. G. (2014). The evidence in support of physicians and health care providers as physical activity role models. American Journal of Lifestyle Medicine, 1559827613520120.

20. Hicks, M., McDermott, L. L., Rouhana, N., Schmidt, M., Seymour, M. W., \& Sullivan, T. (2008). Nurses' body size and public confidence in ability to provide health education. Journal of Nursing Scholarship, 40(4), 349-354.

21. Miller, S. K., Alpert, P. T., \& Cross, C. L. (2008). Overweight and obesity in nurses, advanced practice nurses, and nurse educators. Journal of the American Academy of Nurse Practitioners, 20(5), 259-265. 
22. Zhu, D., Norman, I. J., \& While, A. E. (2011). The relationship between health professionals' weight status and attitudes towards weight management: a systematic review. Obesity Reviews, 12(5), e324-e337.

23. Aranda, K. and McGreevy, D. (2014). Embodied empathy-in-action: Overweight nurses' experiences of their interactions with overweight patients. Nursing inquiry, 21(1), 3038.

24. Zitkus, B.S. (2011). The relationship among registered nurses' weight status, weight loss regimens, and successful or unsuccessful weight loss. Journal of the American Academy of Nurse Practitioners, 23(2), 110-116.

25. Bogossian, F. E., Hepworth, J., Leong, G. M., Flaws, D. F., Gibbons, K. S., Benefer, C. A., \& Turner, C. T. (2012). A cross-sectional analysis of patterns of obesity in a cohort of working nurses and midwives in Australia, New Zealand, and the United Kingdom. International Journal of Nursing Studies, 49(6), 727-738.

26. Goon, D. T., Maputle, M. S., Olukoga, A., Lebese, R., Khoza, L. B., \& Ayanwu, F. C. (2013). Overweight, obesity and underweight in nurses in Vhembe and Capricorn districts, Limpopo. South African Journal of Clinical Nutrition, 26(3), 147-149.

27. SCOTPHO, 2014. The Scottish Health Survey. Scottish Public Health Observatory. Last updated 10 March 2014. Available online at:

http://www.scotpho.org.uk/publications/overview-of-key-data-sources/surveys-crosssectional/scottish-health-survey.

28. Scottish Centre for Social Research. (2008). Scottish Health Survey'08 user guide. London: Scottish Centre for Social Research. Online at: http://doc.ukdataservice.ac.uk/doc/6383/mrdoc/pdf/6383data_documents.pdf. 
29. Office for National Statistics (ONS) (2010) Standard Occupational Classification 2010. London: ONS.

30. Rose, D., Prevalin, D. and O'Reilly, K. (2005) The National Statistics Socio-economic classification: origins, development and use, Basingstoke, Palgrave MacMillan.

31. Power, C., Graham, H., Due, P., Hallqvist, J., Joung, I., Kuh, D., Lynch, J. (2005) The contribution of childhood and adult socioeconomic position to adult obesity and smoking behaviour: an international comparison. International Journal of Epidemiology, 34(2), 335-344.

32. Stephens, S. K., Cobiac, L. J., \& Veerman, J. L. (2014). Improving diet and physical activity to reduce population prevalence of overweight and obesity: An overview of current evidence. Preventive Medicine, 62, 167-178.

33. Malik S, Blake H, Batt M (2011) How healthy are our nurses? New and registered nurses compared. British Journal of Nursing, 20(8): 489-496.

34. Amani, R., \& Gill, T. (2013). Shiftworking, nutrition and obesity: implications for workforce health-a systematic review. Asia Pacific Journal of Clinical Nutrition, 22(4), 698.

35. Zhao, I., \& Turner, C. (2008). The impact of shift work on people's daily health habits and adverse health outcomes.

36. Matheson, A., O'Brien, L., \& Reid, J. A. (2014). The impact of shiftwork on health: a literature review. Journal of Clinical Nursing, 23(23-24), 3309-3320.

37. Harrington, J. M. (2001). Health effects of shift work and extended hours of work. Occupational and Environmental Medicine, 58(1), 68-72.

38. NHS England (2014) Five year forward view. NHS England, London. 
39. Blake, H., Malik, S., Mo, P. K., \& Pisano, C. (2011). 'Do as I say, but not as I do': Are next generation nurses role models for health?. Perspectives in public health, 131(5), 231-239.

40. Hawker CL (2012) Physical activity and mental well-being in student nurses. Nurse Education Today, 32(3): 325-331. 


\section{TABLES}

Table 1: SOC2000 and SOC2010 codes for occupational groups

\begin{tabular}{|c|c|c|}
\hline Occupational categories & $\begin{array}{l}\text { SOC2000 } \\
(2008-2011)\end{array}$ & $\begin{array}{l}\text { SOC2010 } \\
\text { Code (2012) }\end{array}$ \\
\hline Nurse & 3211 & 2231 \\
\hline \multicolumn{3}{|l|}{ Other health professional } \\
\hline Medical practitioners & 2211 & 2211 \\
\hline Psychologists & 2212 & 2212 \\
\hline Pharmacist & 2213 & 2213 \\
\hline Ophthalmic opticians & 2214 & 2214 \\
\hline Dental practitioners & 2215 & 2215 \\
\hline Medical radiographers & 3214 & 2217 \\
\hline Podiatrists & 3215 & 2218 \\
\hline Physiotherapists & 3221 & 2221 \\
\hline Occupational therapists & 3222 & 2222 \\
\hline Speech and language therapists & 3223 & 2223 \\
\hline Therapy professionals (n.e.c.) & 3229 & 2229 \\
\hline Midwives & 3212 & 2232 \\
\hline \multicolumn{3}{|l|}{ Unqualified care worker } \\
\hline Nursing auxiliaries and assistants & 6111 & 6141 \\
\hline Care workers and home carers & 6115 & 6145 \\
\hline Senior care workers & - & 6146 \\
\hline Non-health occupations & $\begin{array}{l}\text { All other } \\
\text { codes }\end{array}$ & $\begin{array}{l}\text { All other } \\
\text { codes }\end{array}$ \\
\hline
\end{tabular}

Note: ${ }^{1}$ N.E.C $=$ Not Elsewhere Classified. 
Table 2: Sample sociodemographic characteristics

\begin{tabular}{|c|c|c|c|c|c|c|c|c|c|c|}
\hline & \multicolumn{2}{|c|}{$\begin{array}{l}\text { Nurses } \\
(n=411)\end{array}$} & \multicolumn{2}{|c|}{$\begin{array}{l}\text { Other Health } \\
\text { Care } \\
\text { Professionals } \\
\quad(n=320)\end{array}$} & \multicolumn{2}{|c|}{$\begin{array}{l}\text { Unqualified } \\
\text { Care Staff } \\
(n=685)\end{array}$} & \multicolumn{2}{|c|}{$\begin{array}{l}\text { Non-health } \\
\text { Related } \\
\text { Occupations } \\
(n=12,067)\end{array}$} & \multicolumn{2}{|c|}{$\begin{array}{c}\text { Total } \\
(n=13,483)\end{array}$} \\
\hline & $\mathrm{n}$ & $\%$ & $\mathrm{n}$ & $\%$ & $\mathrm{n}$ & $\%$ & $\mathrm{n}$ & $\%$ & $\mathrm{n}$ & $\%$ \\
\hline \multicolumn{11}{|l|}{ Survey } \\
\hline 2008 & 65 & 15.8 & 49 & 15.3 & 127 & 18.5 & 2349 & 19.5 & 2590 & 19.2 \\
\hline 2009 & 98 & 23.8 & 73 & 22.8 & 142 & 20.7 & 2793 & 23.1 & 3106 & 23.0 \\
\hline 2010 & 80 & 19.5 & 81 & 25.3 & 159 & 23.2 & 2519 & 20.9 & 2839 & 21.1 \\
\hline 2011 & 91 & 22.1 & 71 & 22.2 & 163 & 23.8 & 2701 & 22.4 & 3026 & 22.4 \\
\hline 2012 & 77 & 18.7 & 46 & 14.4 & 94 & 13.7 & 1705 & 14.1 & 1922 & 14.3 \\
\hline \multicolumn{11}{|l|}{ Gender } \\
\hline Males & 31 & 7.5 & 87 & 27.2 & 102 & 14.9 & 6198 & 51.4 & 6418 & 47.6 \\
\hline Females & 380 & 92.5 & 233 & 72.8 & 583 & 85.1 & 5869 & 48.6 & 7065 & 52.4 \\
\hline \multicolumn{11}{|l|}{ Age } \\
\hline$\leq 29$ & 32 & 7.8 & 40 & 12.5 & 82 & 12.0 & 1689 & 14.0 & 3080 & 22.8 \\
\hline $30-34$ & 37 & 9.0 & 45 & 14.1 & 37 & 5.4 & 1244 & 10.3 & 1735 & 12.9 \\
\hline $35-39$ & 39 & 9.5 & 41 & 12.8 & 77 & 11.2 & 1419 & 11.8 & 1978 & 14.7 \\
\hline $40-44$ & 68 & 16.5 & 52 & 16.3 & 109 & 15.9 & 1809 & 15.0 & 2457 & 18.2 \\
\hline $45-49$ & 100 & 24.3 & 50 & 15.6 & 105 & 15.3 & 1920 & 15.9 & 2589 & 19.2 \\
\hline $50-54$ & 70 & 17.0 & 43 & 13.4 & 116 & 16.9 & 1647 & 13.6 & 2256 & 16.7 \\
\hline $55-59$ & 42 & 10.2 & 32 & 10.0 & 104 & 15.2 & 1386 & 11.5 & 1901 & 14.1 \\
\hline$\geq 60$ & 23 & 5.6 & 17 & 5.3 & 55 & 8.0 & 953 & 7.9 & 1298 & 9.6 \\
\hline \multicolumn{11}{|l|}{ Parental NS-SEC } \\
\hline Managerial and professional & 160 & 38.9 & 202 & 63.1 & 150 & 21.9 & 4143 & 34.3 & 4655 & 34.5 \\
\hline Intermediate & 56 & 13.6 & 28 & 8.8 & 68 & 9.9 & 1293 & 10.7 & 1445 & 10.7 \\
\hline $\begin{array}{l}\text { Small employers/own } \\
\text { account }\end{array}$ & 50 & 12.2 & 34 & 10.6 & 83 & 12.1 & 1394 & 11.6 & 1561 & 11.6 \\
\hline Lower supervisory/technical & 50 & 12.2 & 30 & 9.4 & 114 & 16.6 & 1784 & 14.8 & 1978 & 14.7 \\
\hline Semi-routine & 95 & 23.1 & 26 & 8.1 & 270 & 39.4 & 3453 & 28.6 & 3844 & 28.5 \\
\hline \multicolumn{11}{|l|}{ BMI } \\
\hline Mean (Standard Deviation) & 27.9 & $(5.0)$ & 26.1 & $(4.6)$ & 28.5 & $(5.8)$ & 27.8 & $(5.0)$ & 27.8 & (5.0) \\
\hline$<18.50^{\mathrm{a}}$ & 1 & 0.24 & 5 & 1.56 & 6 & 0.88 & 86 & 0.71 & 98 & 0.73 \\
\hline$<24.99$ & 127 & 30.9 & 156 & 48.8 & 216 & 31.5 & 3751 & 31.1 & 4250 & 31.5 \\
\hline 25.00-29.99 & 163 & 39.7 & 109 & 47.2 & 228 & 33.3 & 4801 & 39.8 & 5301 & 39.3 \\
\hline $30.00+^{b}$ & 121 & 29.4 & 55 & 17.2 & 241 & 35.2 & 3515 & 29.1 & 3932 & 29.2 \\
\hline
\end{tabular}

Notes: ${ }^{a}$ Underweight included with normal in analysis due to small numbers. ${ }^{\mathrm{b}}$ Morbidly obese included with obese in analysis due to small numbers. 
Table 3: Overweight by occupational group

\begin{tabular}{|c|c|c|c|c|c|c|}
\hline \multirow[b]{4}{*}{ Occupational group } & \multicolumn{6}{|c|}{ Overweight (BMI $\geq 25.00$ ) } \\
\hline & \multicolumn{3}{|c|}{ Unweighted } & \multicolumn{3}{|c|}{ Weighted } \\
\hline & \multirow[b]{2}{*}{$\%$} & \multicolumn{2}{|l|}{$95 \% \mathrm{Cl}$} & \multirow[b]{2}{*}{$\%$} & \multicolumn{2}{|l|}{$95 \% \mathrm{Cl}$} \\
\hline & & Lower & Upper & & Lower & Upper \\
\hline Nurses & 69.10 & 64.63 & 73.57 & 69.58 & 65.02 & 74.15 \\
\hline Other health care professionals & 51.25 & 45.77 & 56.73 & 49.39 & 44.10 & 54.68 \\
\hline Unqualified care staff & 68.47 & 64.99 & 71.95 & 69.16 & 65.53 & 72.80 \\
\hline Non-health related occupations & 68.92 & 68.09 & 69.74 & 67.61 & 66.79 & 68.42 \\
\hline Total & 68.48 & 67.69 & 69.26 & 67.29 & 66.51 & 68.06 \\
\hline
\end{tabular}


Table 4: Binary logistic regression model

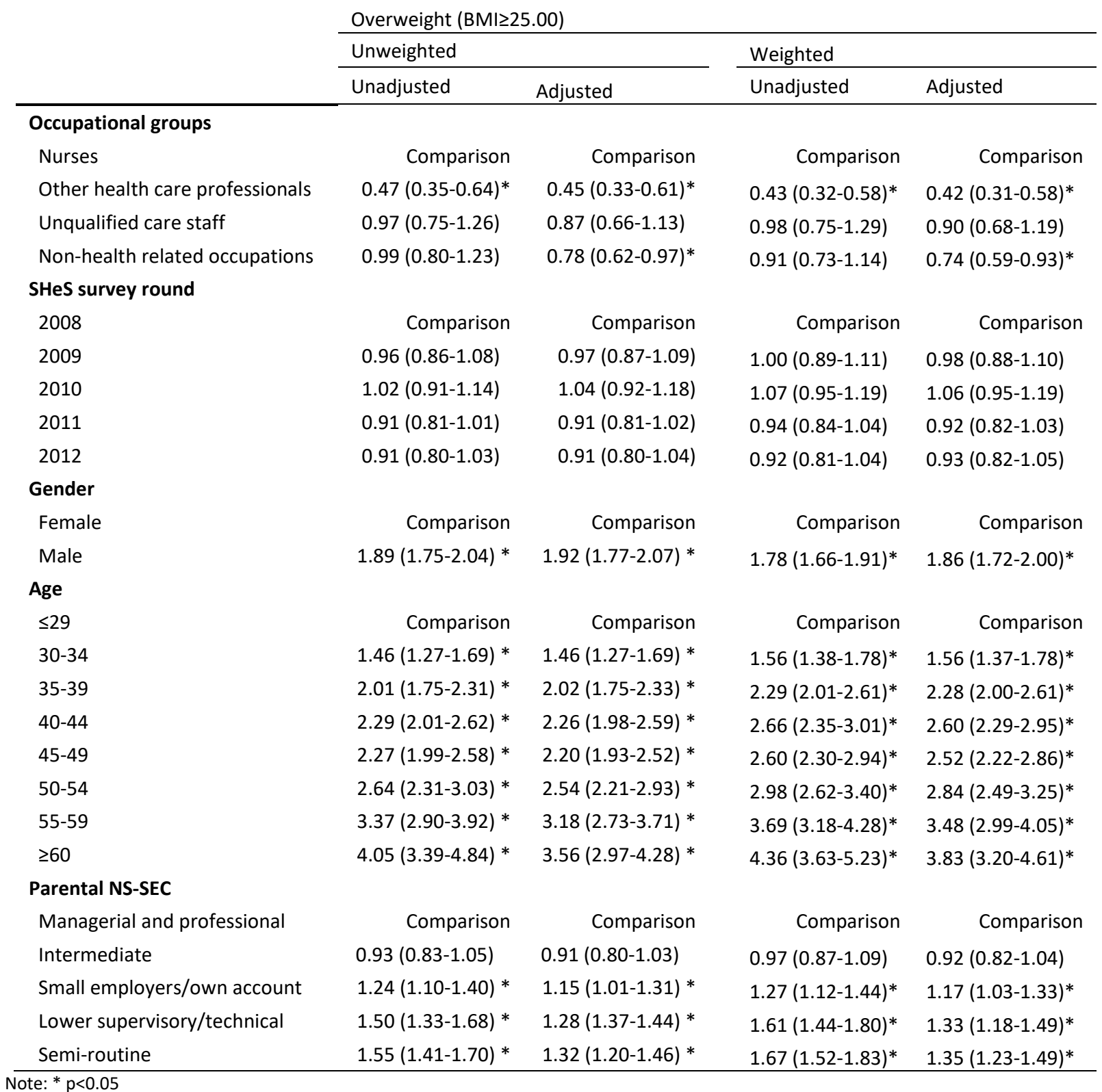

